\title{
Low-Flow Nasal Cannula Hydrogen Therapy
}

\author{
Motoaki Sano $^{\text {a, b, d }}$, Kohsuke Shirakawa ${ }^{\text {a, b }}$, Yoshinori Katsumata ${ }^{\text {a, b }}$, \\ Genki Ichihara $^{a, b}$, Eiji Kobayashia, b, c
}

\begin{abstract}
Background: Molecular hydrogen $\left(\mathrm{H}_{2}\right)$ is a biologically active gas that is widely used in the healthcare sector. In recent years, on-site $\mathrm{H}_{2}$ gas generators, which produce high-purity $\mathrm{H}_{2}$ by water electrolysis, have begun to be introduced in hospitals, clinics, beauty salons, and fitness clubs because of their ease of use. In general, these generators produce $\mathrm{H}_{2}$ at a low-flow rate, so physicians are concerned that an effective blood concentration of $\mathrm{H}_{2}$ may not be ensured when the gas is delivered through a nasal cannula. Therefore, this study aimed to evaluate blood concentrations of $\mathrm{H}_{2}$ delivered from an $\mathrm{H}_{2}$ gas generator via a nasal cannula.
\end{abstract}

Methods: We administered $100 \% \mathrm{H}_{2}$, produced by an $\mathrm{H}_{2}$ gas generator, at a low-flow rate of $250 \mathrm{~mL} / \mathrm{min}$ via a nasal cannula to three spontaneously breathing micro miniature pigs. An oxygen mask was placed over the nasal cannula to administer oxygen while minimizing $\mathrm{H}_{2}$ leakage, and a catheter was inserted into the carotid artery to monitor the arterial blood $\mathrm{H}_{2}$ concentration.

Results: During the first hour of $\mathrm{H}_{2}$ inhalation, the mean (standard error (SE)) $\mathrm{H}_{2}$ concentrations and saturations in the arterial blood of the three pigs were $1,560(413) \mathrm{nL} / \mathrm{mL}$ and $8.85 \%(2.34 \%) ; 1,190$ (102) $\mathrm{nL} / \mathrm{mL}$ and $6.74 \%(0.58 \%)$; and $1,740(181) \mathrm{nL} / \mathrm{mL}$ and $9.88 \%$ $(1.03 \%)$, respectively. These values are comparable to the concentration one would expect if $100 \%$ of the $\mathrm{H}_{2}$ released from the $\mathrm{H}_{2}$ gas generator is taken up by the body.

Conclusions: Inhalation of $100 \% \mathrm{H}_{2}$ produced by an $\mathrm{H}_{2}$ gas generator, even at low-flow rates, can increase blood $\mathrm{H}_{2}$ concentrations to levels that previous non-clinical and clinical studies demonstrated to be therapeutically effective. The combination of a nasal cannula and an oxygen mask is a convenient way to reduce $\mathrm{H}_{2}$ leakage while maintaining oxygenation.

Manuscript submitted August 12, 2020, accepted August 21, 2020

Published online September 21, 2020

aDepartment of Cardiology, Keio University School of Medicine, 35 Shinanomachi, Shinjuku-ku, Tokyo 160-8582, Japan

${ }^{\mathrm{b}}$ Center for Molecular Hydrogen Medicine, Keio University, 2-15-45 Mita, Minato-ku, Tokyo 108-8345, Japan

'Department of Organ Fabrication, Keio University School of Medicine, 35 Shinanomachi, Shinjuku-ku, Tokyo 160-8582, Japan

${ }^{\mathrm{d} C}$ Corresponding Author: Motoaki Sano, Department of Cardiology, Keio University School of Medicine, 35 Shinanomachi, Shinjuku-ku, Tokyo 160-8582, Japan.Email: msano@a8.keio.jp

doi: https://doi.org/10.14740/jocmr4323
Keywords: Hydrogen gas; Pharmacokinetics; Hydrogen gas inhaler; Hydrogen gas generator; Micro miniature pig; Combined oxygen masks with nasal cannula; COVID-19

\section{Introduction}

Molecular hydrogen $\left(\mathrm{H}_{2}\right)$ has a wide range of benefits, ranging from improving health to preventing and treating disease. The health benefits include improving mood, reducing anxiety, and counteracting an overactive sympathetic nervous system [1]. In terms of disease prevention and treatment, $\mathrm{H}_{2}$ has been used to treat many diseases, including lifestyle diseases [2]; immune diseases, such as atopic dermatitis [2], hay fever [3], and chronic rheumatoid arthritis [4]; respiratory diseases, such as asthma [5], chronic obstructive pulmonary disease [6], and pneumonia caused by the coronavirus disease 2019 (COVID-19) [7]; neurological diseases, such as depression [8], dementia [9], stroke [10], post-cardiac arrest syndrome [11, 12], subarachnoid hemorrhage [13], and traumatic injury from blast shock waves [14]; myocardial infarction [15-17]; chronic kidney disease [18]; sepsis [19] and hemorrhagic shock [20, 21]; and cancer [22].

$\mathrm{H}_{2}$ exerts antioxidant and anti-inflammatory effects. As a molecular mechanism, ex vivo experiments have been shown that $\mathrm{H}_{2}$ reduces hydroxyl radical $(\cdot \mathrm{OH})$ and peroxynitrite [10] and suppresses the propagation of the radical reaction in lipid bilayers [23]. Clinical and animal studies have shown that $\mathrm{H}_{2}$ therapy reduces circulating levels of oxidative stress markers and proinflammatory cytokines in shock from a wide range of etiologies $[11,24]$.

$\mathrm{H}_{2}$ can be supplied from a high-pressure gas cylinder [11, $12,15-17]$, generated from a hydrogen-absorbing alloy [25, 26] or hydride, or produced by electrolysis of water [7]. In recent years, on-site $\mathrm{H}_{2}$ gas generators, which generate highpurity $\mathrm{H}_{2}$ by electrolysis of water, have begun to be introduced in hospitals, clinics, beauty salons, and fitness clubs because of their ease of handling.

Recently, the results of a clinical study on the therapeutic effect of $\mathrm{H}_{2}$ inhalation in COVID-19 pneumonia were reported from China [7]. In this study, the researchers used an $\mathrm{H}_{2}$ gas generator as the source of $\mathrm{H}_{2}$ and administered a mixture of $\mathrm{H}_{2}$ and oxygen $\left(\mathrm{O}_{2}\right)$ gas $\left(66 \% \mathrm{H}_{2} ; 33 \% \mathrm{O}_{2}\right)$, obtained by electrolysis of water, by a nasal cannula. An improvement in clinical symptoms was seen in a significantly higher percentage of patients in the treatment group, who inhaled a mixture of $\mathrm{H}_{2}$ and 
$\mathrm{O}_{2}$, than in patients in the control group, who received classic oxygen therapy.

Because the $\mathrm{H}_{2}$ produced from an on-site $\mathrm{H}_{2}$ gas generator has a low-flow rate, clinicians are concerned that when $\mathrm{H}_{2}$ is inhaled through a nasal cannula, blood concentrations may be lower than expected because of leakage of $\mathrm{H}_{2}$ from the nostrils. We hypothesized that the $\mathrm{H}_{2}$ concentration could be better ensured if patients wore an oxygen mask over the nasal cannula. Therefore, we tested this hypothesis in pigs, whose organs are similar in size, anatomy, and physiology to those of humans.

\section{Materials and Methods}

\section{Animals}

The present study was designed according to the principles of the ARRIVE (Animal Research: Reporting of In Vivo Experiments) guidelines [27]. The experiments were performed in accordance with our institutional guidelines and with the Japanese law on the protection and management of animals. Ethical approval was granted by the Research Council and Animal Care and Use Committee of Keio University (approval no: 12094-(8)).

The study was performed in three micro miniature pigs, weighing $16.8 \mathrm{~kg}, 15.5 \mathrm{~kg}$, and $16.8 \mathrm{~kg}$, which were housed in separate cages under temperature- and light-controlled conditions (12-h light/dark cycle) and provided with food and water ad libitum (Supplementary Material 1, www.jocmr.org). Before surgery, the pigs were fasted for $12 \mathrm{~h}$, with free access to water. Then, a xylazine hydrochloride intramuscular injection was given $15 \mathrm{~min}$ before induction of isoflurane anesthesia. Experiments were performed under anesthesia, and isoflurane was administered to maintain immobilization.

\section{Catheter insertion}

First, a central venous catheter $(14$ gauge $\times 70 \mathrm{~cm}$; Argyle $)$ equipped with a three-way stopcock (TERUMO terufusion three-way stopcock, R type) was filled with heparinized saline. Once at a sufficient depth of anesthesia, each pig was placed in the supine position. A vertical incision of about 10 $\mathrm{cm}$ was made in the right side of the neck to expose about $3 \mathrm{~cm}$ of the right external jugular vein and the right internal carotid artery. The peripheral side of the right internal carotid artery was ligated with a 1-0 silk thread, a bulldog clip was applied to the medial side, an incision was made, and a catheter was advanced about $5 \mathrm{~cm}$ into the artery and secured. Surgery was performed by the senior author of this paper (EK), a surgeon who has completed more than 200 clinical transplant operations and is a steering member of the transplantation society and a permanent director of the transplantation society of Japan. Blood was collected from the intravascular catheters at $0,10,30$, and 60 min after starting $\mathrm{H}_{2}$ inhalation, and the blood $\mathrm{H}_{2}$ concentration was measured by gas chromatography.

\section{$\mathrm{H}_{2}$ gas generator}

This study used the $\mathrm{H}_{2}$ inhaler H2JI1, manufactured by Doctors Man Co, Ltd. The inhaler uses a proton-exchange membrane (PEM) water electrolysis system that can continuously generate high purity $(>99.999 \%) \mathrm{H}_{2}$ at a flow rate of $250 \mathrm{~mL} /$ min, $24 \mathrm{~h}$ a day, 365 days a year (Supplementary Material 2, www.jocmr.org).

\section{$\mathrm{H}_{2}$ inhalation}

The length of the part of the nasal cannula (Nakamura Medical Industry Co., Ltd.) that is inserted into the nostrils was modified from the original $12 \mathrm{~mm}$ to $62 \mathrm{~mm}$ by inserting a $10-\mathrm{mm}$ silicon tube with a total length of $60 \mathrm{~mm}$, an outer diameter of $3 \mathrm{~mm}$, and an inner diameter of $1.5 \mathrm{~mm}$ into the left and right outlets. We then adjusted the nostril inserts of the nasal cannula to fit the shape of a pig's nose. The nasal cannula was inserted deep into the nasal cavity of a pig under spontaneous breathing, and $100 \% \mathrm{H}_{2}$ produced from the $\mathrm{H}_{2}$ gas generator was administered at a flow rate of $250 \mathrm{~mL} / \mathrm{min}$ (Fig. 1).

A veterinary anesthesia mask (Shinano Manufacturing Co., Ltd.) was placed over the nasal cannula and an ADS 1000 (model: 2000) veterinary anesthesia delivery system (Tokushima Iryoki Co., Ltd.) was used to deliver a mixture of $\mathrm{O}_{2}$ and isoflurane (Fig. 2). The flow rate of the $\mathrm{O}_{2}$ /isoflurane gas mixture was maintained above $6 \mathrm{~L} / \mathrm{min}$ to avoid re-inhalation of exhaled carbon dioxide $\left(\mathrm{CO}_{2}\right)$ that would stay in the mask.

\section{Measurement of $\mathrm{H}_{2}$ concentration}

To measure the blood $\mathrm{H}_{2}$ concentration, we first inserted a needle into the rubber lid of a 13.5-mL sealed vial, extracted 1 $\mathrm{mL}$ of air and injected $1 \mathrm{~mL}$ of blood. To prevent outgassing, we immediately applied wax to the rubber lid to seal the injection hole. $\mathrm{H}_{2}$ in the blood was released into the air phase in the closed vial. Some of the air phase $(0.2 \mathrm{~mL}, 0.4 \mathrm{~mL}$, or $1 \mathrm{~mL}$, depending on the $\mathrm{H}_{2}$ concentration) was collected from the vial, and the $\mathrm{H}_{2}$ concentration was measured by gas chromatography (TRIlyzer mBA-3000, Taiyo, Co., Ltd.). A calibration curve was obtained by using standard $\mathrm{H}_{2}$ gas of $0,5,50$, and $130 \mathrm{ppm}$. Each sample was measured twice. The concentration of the sample taken before $\mathrm{H}_{2}$ inhalation was subtracted as the background [26].

\section{Results}

In all three pigs, the blood $\mathrm{H}_{2}$ concentrations in the carotid arteries before inhalation were almost 0 , reached peak levels by $10 \mathrm{~min}$ after the start of inhalation and remained at approximately the same level until 60 min later. The means (standard error (SE)) of the $\mathrm{H}_{2}$ concentrations and saturations in the blood from the carotid arteries during $\mathrm{H}_{2}$ inhalation in the three pigs were 1,560 (413) $\mathrm{nL} / \mathrm{mL}$ and $8.85 \%$ (2.34\%); 1,190 (102) $\mathrm{nL} / \mathrm{mL}$ and $6.74 \%(0.58 \%)$; and $1,740(181 \mathrm{~nL} / \mathrm{mL})$ and $9.88 \%$ 


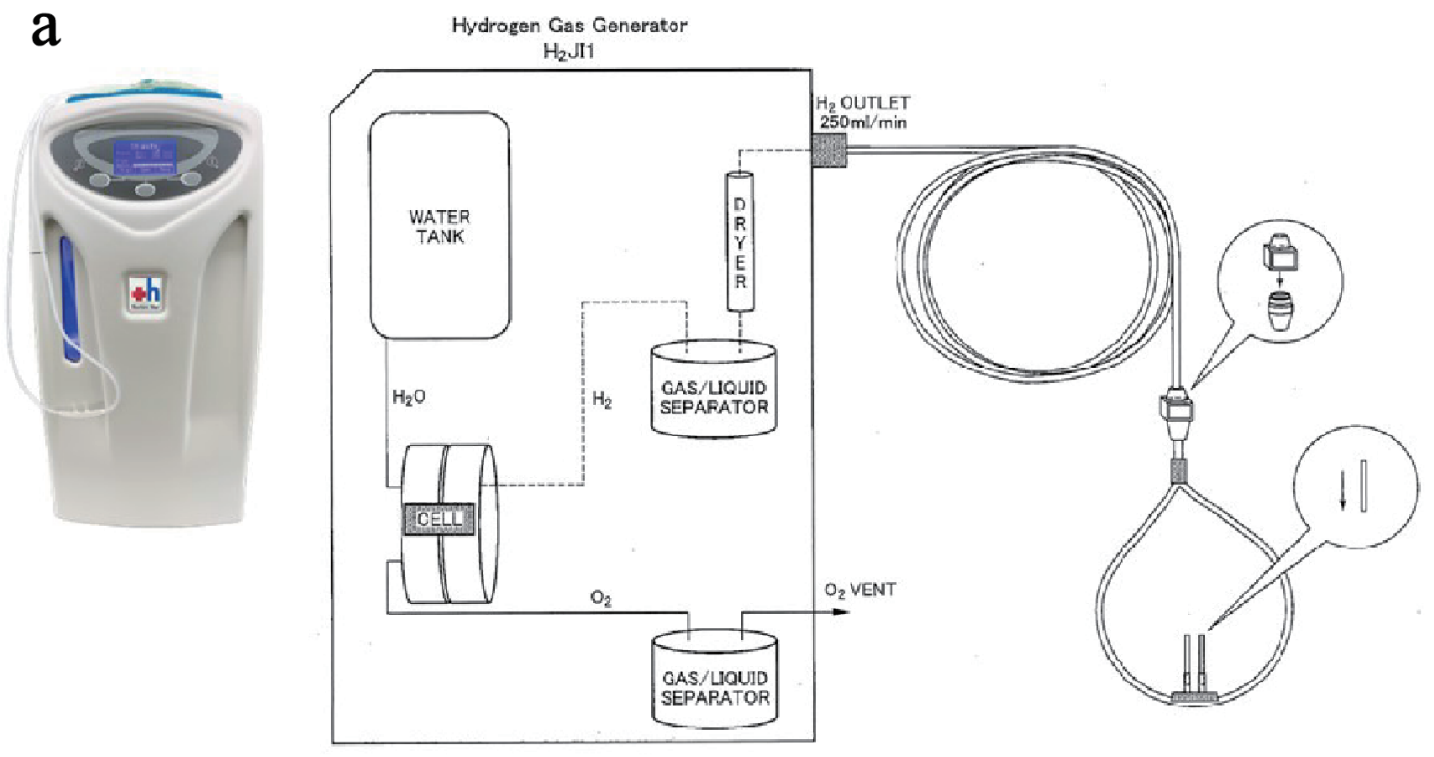

b

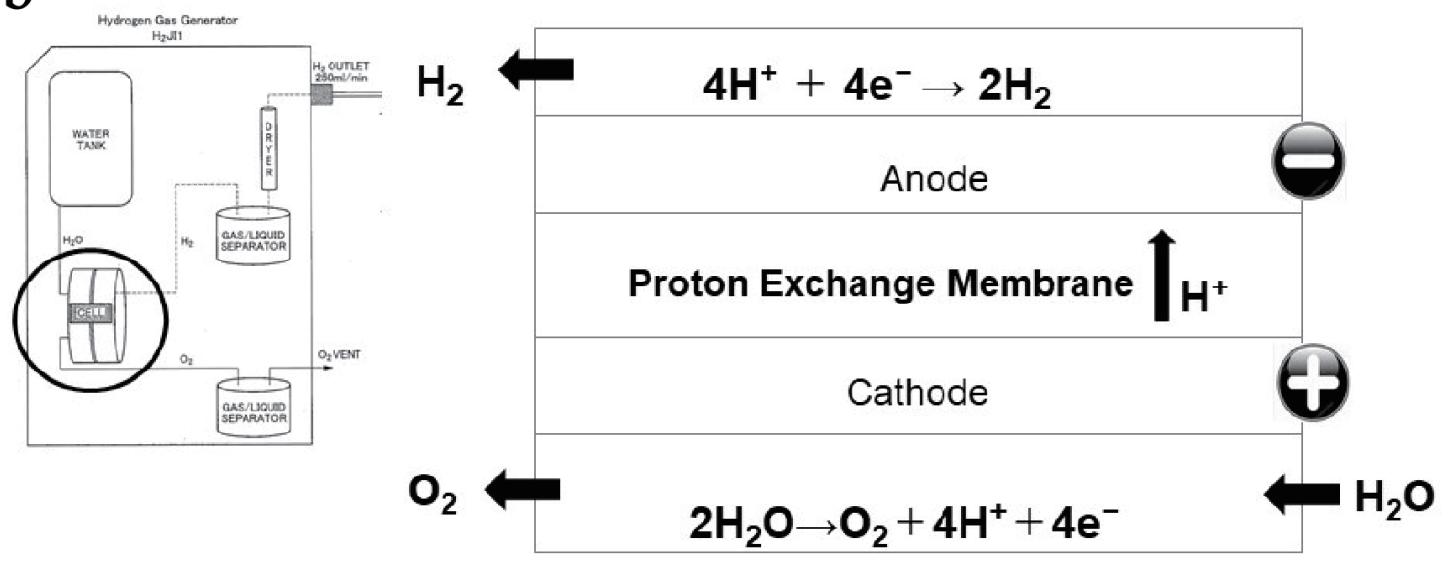

Figure 1. Hydrogen gas $\left(\mathrm{H}_{2}\right)$ supply system from an $\mathrm{H}_{2}$ gas generator. (a) Specifications of $\mathrm{H}_{2}$ gas generator. The $\mathrm{H}_{2}$ gas generator is capable of continuously administering $100 \% \mathrm{H}_{2}$ at a flow rate of $250 \mathrm{~mL} / \mathrm{min}, 24 \mathrm{~h}$ a day, 365 days a year. (b) Structure of the electrolyzer. The electrolysis reaction occurs in an electrolyzer, which consists of two electrodes separated by an ion exchange membrane. When voltage is continuously applied to the electrodes in the electrolyzer, two electrons are removed from a water molecule at the anode (negative electrode) to form one oxygen molecule $\left(\mathrm{O}_{2}\right)$ and four hydrogen ions. The $\mathrm{O}_{2}$ is safely released into the atmosphere, and the four hydrogen ions pass through the ion exchange membrane and are attracted to the cathode. At the cathode (positive electrode), electrons are combined with hydrogen ions to produce hydrogen gas $\left(\mathrm{H}_{2}\right)$.

$(1.03 \%)$, respectively (Fig. 3 and Supplementary Material 3, www.jocmr.org).

We calculated the fraction of inspiratory $\mathrm{H}_{2}$ from the $\mathrm{H}_{2}$ flow rate produced by the $\mathrm{H}_{2}$ gas generator, as follows: The $\mathrm{H}_{2}$ flow rate per second was $250 / 60 \mathrm{~mL}$, so at a respiratory rate of 20 breaths per minute, the expected volume of $\mathrm{H}_{2}$ that would accumulate in the nasopharynx during 3 -s inhalation time and exhalation was $250 / 60 \mathrm{~mL} \times 3=12.5 \mathrm{~mL}$. If $\mathrm{H}_{2}$ was inhaled without leakage from the nostrils, the fraction of inspiratory $\mathrm{H}_{2}$ would be $12.5 / 150=0.083$, or $8.3 \%$ at a tidal volume of 150 $\mathrm{mL}$. In short, the measured $\mathrm{H}_{2}$ concentration (saturation) in the arterial blood agreed closely with the expected value predicted from the $\mathrm{H}_{2}$ gas generator's flow rate.

\section{Discussion}

In this experiment to establish a methodology for efficiently delivering $100 \% \mathrm{H}_{2}$ with an on-site $\mathrm{H}_{2}$ gas generator, we administered $\mathrm{H}_{2}$ to three pigs through a nasal cannula with an oxygen mask worn over it. Our study showed that an effective blood $\mathrm{H}_{2}$ concentration can be achieved even with the lowflow rates of the $\mathrm{H}_{2}$ gas generator.

The $\mathrm{H} 2 \mathrm{JI} 1 \mathrm{H}_{2}$ gas generator used in this study consistently 

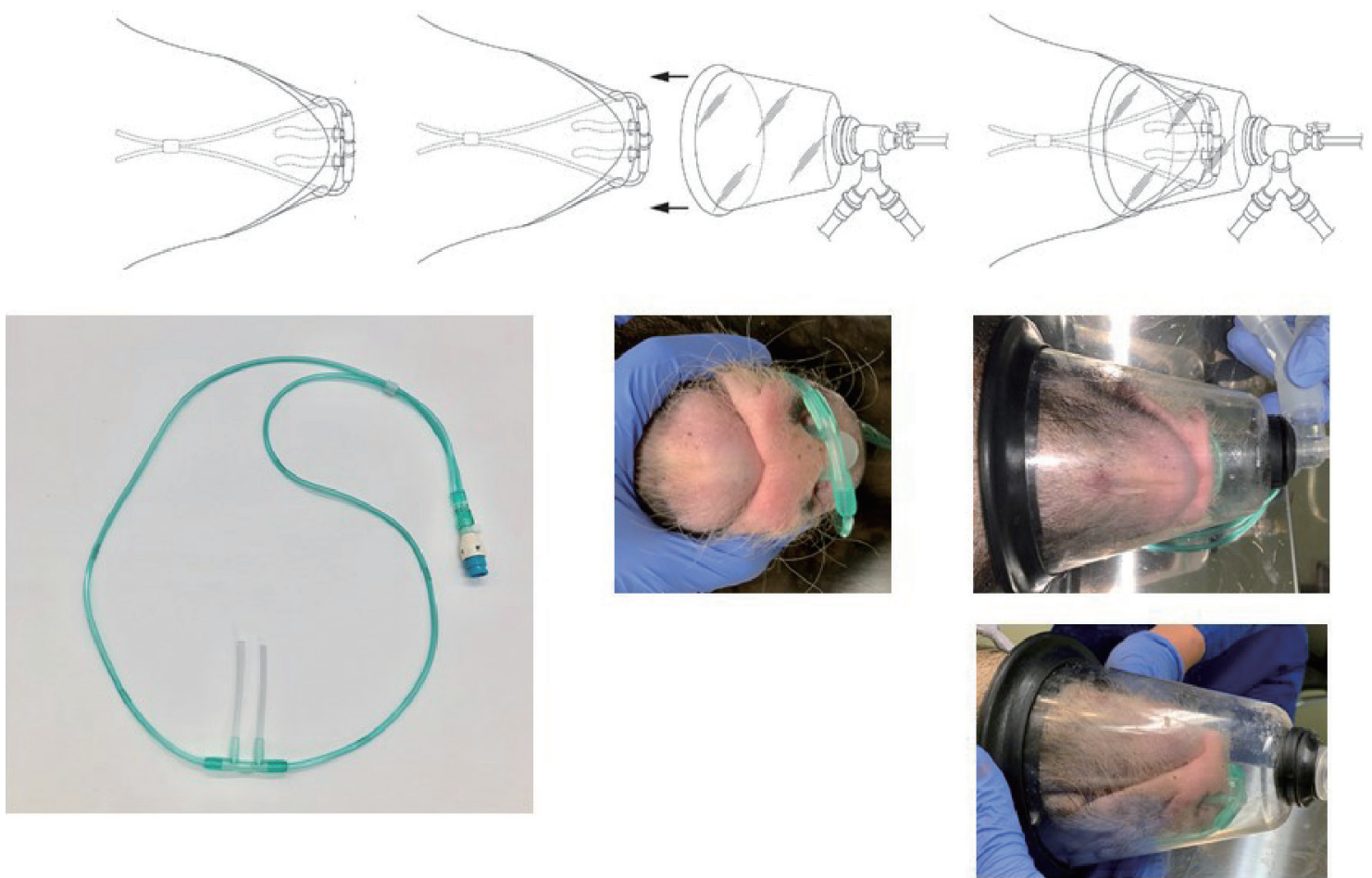

Figure 2. Nasal cannula and oxygen mask for micro miniature pigs. The length of the part of the nasal cannula that is inserted into the nostrils was modified from the original $12 \mathrm{~mm}$ to $62 \mathrm{~mm}$ by inserting a $10-\mathrm{mm}$ silicon tube. The nasal cannula was then inserted deep into the nasal cavity of a spontaneously breathing pig, and $100 \% \mathrm{H}_{2}$ produced by the $\mathrm{H}_{2}$ gas generator was administered at a flow rate of $250 \mathrm{~mL} / \mathrm{min}$. A veterinary anesthesia mask was placed over the nasal cannula, and a veterinary anesthesia delivery system was used to supply oxygen and anesthesia to the animals.

supplies $100 \% \mathrm{H}_{2}$ with a purity greater than $99.999 \%$ at a flow rate of $250 \mathrm{~mL} / \mathrm{min}$. If such a generator is used to administer $\mathrm{H}_{2}$ to a human, at a tidal volume of $500 \mathrm{~mL}$ and 20 breaths per

\section{$\mathrm{H}_{2}$ concentration in carotid artery $(\mathrm{nL} / \mathrm{mL})$}

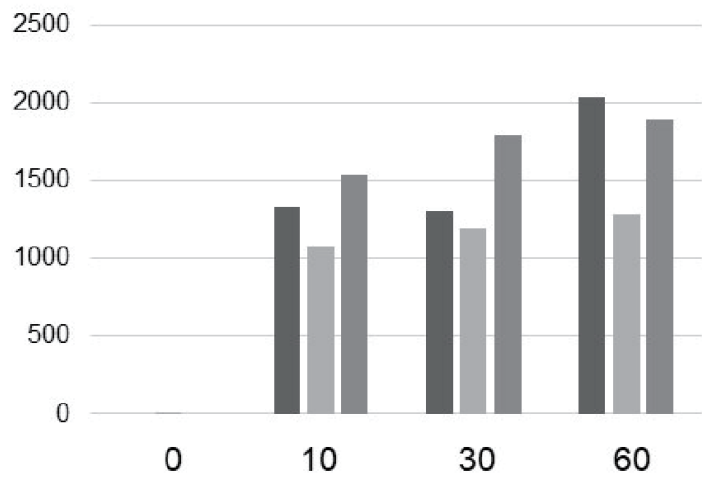

Time after $\mathrm{H}_{2}$ inhalation, min

$$
\text { MMP1 MMP2 } \quad \text { MMP3 }
$$

minute the expected inspired $\mathrm{H}_{2}$ concentration would be $2.5 \%$. This concentration would be even higher in the elderly, who have a lower tidal volume.

\section{$\mathrm{H}_{2}$ saturation level in carotid artery}

(\%)

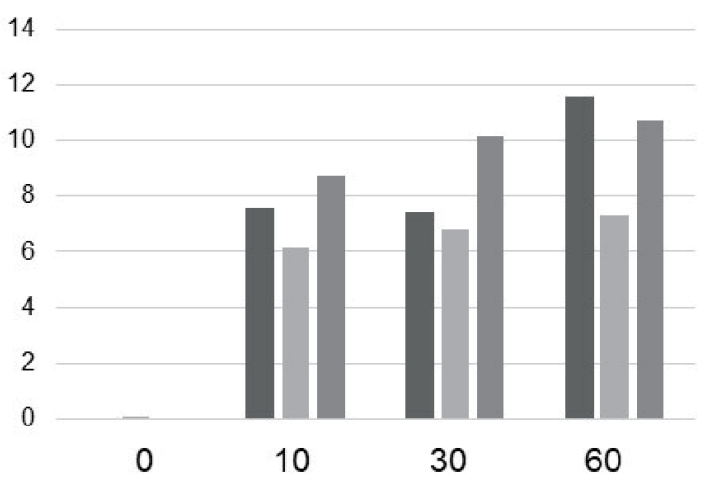

Time after $\mathrm{H}_{2}$ inhalation, min

MMP1 MMP2 $\quad$ MMP3

Figure 3. Carotid artery hydrogen $\left(\mathrm{H}_{2}\right)$ concentration in three micro miniature pigs (MMP1 - 3) during $\mathrm{H}_{2}$ inhalation. The concentration of $\mathrm{H}_{2}$ when it is completely dissolved in water is $17,600 \mathrm{~nL} / \mathrm{mL}$. Therefore, $\mathrm{H}_{2}$ saturation was determined by dividing the measured value (concentration) by $17,600 \mathrm{~nL} / \mathrm{mL}$. 
In our previous clinical study to evaluate the safety and efficacy of $\mathrm{H}_{2}$ inhalation in patients with ST-segment elevation myocardial infarction [17], we delivered $\mathrm{H}_{2}$ via high-pressure compressed gas cylinders containing a mixture of $\mathrm{H}_{2}(1.3 \%)$, $\mathrm{O}_{2}$, nitrogen, and mixed gases through a mask at a high-flow rate of $10 \mathrm{~L} / \mathrm{min}$. We chose this flow rate to ensure that the concentration of inhaled $\mathrm{H}_{2}$ was $1.3 \%$ because this concentration was confirmed to be effective in reducing infarct size in preclinical studies in dogs [16]. The High-Pressure Gas Safety Act stipulates that when $\mathrm{O}_{2}$ and $\mathrm{H}_{2}$ are mixed under pressure, the $\mathrm{H}_{2}$ concentration must be no greater than $1.3 \%$. In the present study, we found that even though the flow of $100 \% \mathrm{H}_{2}$ generated on site by the $\mathrm{H}_{2}$ gas generator was low, if $\mathrm{H}_{2}$ was administered by a nasal cannula covered with an oxygen mask the arterial blood $\mathrm{H}_{2}$ saturation levels increased to the same levels as when high-flow $1.3 \% \mathrm{H}_{2}$ was administered from compressed gas high-pressure cylinders.

The $\mathrm{H}_{2}$ gas generator is lightweight and portable and can provide $\mathrm{H}_{2}$ anywhere, as long as a power source and pure water are available. Furthermore, the generator can supply $\mathrm{H}_{2}$ continuously for a long time. The generator represents a safe and convenient alternative to high-pressure gas cylinders for $\mathrm{H}_{2}$ inhalation therapy and requires no replenishment of supplies. For example, installing an $\mathrm{H}_{2}$ gas generator at the bedside of a patient with COVID-19 pneumonia with hypoxemia allows the patient to consistently inhale $\mathrm{H}_{2}$ through a nasal cannula. In addition, a suitable mask (face mask, face mask with reservoir, or Venturi mask) can be worn over the nasal cannula, depending on the patient's level of oxygenation. Using this method, a patient can continuously inhale $\mathrm{H}_{2}$ until the pneumonia is cured and the patient is discharged from the hospital. Similarly, patients with mild cases of COVID-19 who are waiting outside a hospital can be given $\mathrm{H}_{2}$ inhalation to prevent their illness becoming more severe.

Although some people experience a headache after inhaling $\mathrm{H}_{2}$, probably due to the dilatation of intracranial blood vessels, no other obvious symptoms are known that could be considered adverse events. Unlike the other bioactive gases, such as nitric oxide (NO), carbon monoxide (CO), and hydrogen sulfide $\left(\mathrm{H}_{2} \mathrm{~S}\right), \mathrm{H}_{2}$ does not bind to the heme in the hemoglobin in the red blood cells. Therefore, the $\mathrm{O}_{2}$ saturation and the partial pressures of $\mathrm{O}_{2}$ and $\mathrm{CO}_{2}$ in arterial blood are unaffected by the inhalation of $\mathrm{H}_{2}$ under steady-state conditions [15].

$\mathrm{H}_{2}$ is the most abundant element in the universe, but it must be produced because it does not occur naturally in a gaseous state on Earth. $\mathrm{H}_{2}$ has been used in laboratories for a variety of applications, including gas chromatography and inductively coupled plasma-mass spectrometry. In addition, it is used in the chemical industry to synthesize ammonia, cyclohexane, and methanol, and in the food industry to hydrogenate oils to make them more solid. Recently, it has been gaining attention as a clean energy source. The best way to produce high-purity $\mathrm{H}_{2}$ on demand is by electrolysis of water. A noteworthy innovation in this technology was water electrolysis with solid polymer electrolyte membranes proposed by General Electric in the early 1970s. Subsequent significant research and development led to a technology for efficiently and stably generating high-purity $\mathrm{H}_{2}$ from pure water $24 \mathrm{~h}$ a day, 365 days a year. This method for generating $\mathrm{H}_{2}$, which has been cultivated by the industry for a long time, has found many uses in humans. The $\mathrm{H}_{2}$ gas generator H2JI1 that we used in our experiments also uses a polymer electrolyte membrane with a durability of more than 50,000 h. The amount of $\mathrm{H}_{2}$ that remains in this device is small, so safety is guaranteed. Also, the device is not subject to the High-Pressure Gas Safety Act. Although the hydrogen gas generator itself is expensive, the durability of the electrolytic cells is long and the running costs are almost zero. Therefore, the cost per hour is as low as less than $\$ 0.47$.

Of course, both high-pressure gas cylinders and $\mathrm{H}_{2}$ gas generators must be used appropriately, depending on a patient's situation. When administering $\mathrm{H}_{2}$ via a ventilator, physicians should choose high-pressure gas cylinders capable of delivering high-flow rates of gas. However, if physicians wish to administer $\mathrm{H}_{2}$ continuously over a long period of time to patients who are breathing spontaneously, we propose that they should consider using a $\mathrm{H}_{2}$ gas generator that can safely produce low-flow but $100 \% \mathrm{H}_{2}$ on-site.

Not much time has passed since $\mathrm{O}_{2}$ inhalation began to be used in medical settings. First, $\mathrm{O}_{2}$ was widely used in industries such as welding and cutting because it supports combustion, but during 1918 - 1920 physicians starting using $\mathrm{O}_{2}$ to treat the "Spanish flu." Citizens rushed to industrial $\mathrm{O}_{2}$ supply companies and queued all night waiting for $\mathrm{O}_{2}$ to arrive. In light of the current COVID-19 pandemic, we propose that now is the time to reconsider the benefits of $\mathrm{H}_{2}$ inhalation therapy.

\section{Supplementary Material}

Suppl 1. Overview of the Micro Miniature Pigs Used in the Experiments.

Suppl 2. Specifications of the Hydrogen Gas Generator H2JI1. Suppl 3. Mean Hydrogen $\left(\mathrm{H}_{2}\right)$ Concentration in the Carotid Artery of Three Micro Miniature pigs (MMP1 - 3).

\section{Acknowledgments}

The authors are grateful to Suga Kato ((Japanese Molecular Hydrogen Promotion Association (JHyPA)) and Mayumi Takeda (JHyPA) for technical assistance.

\section{Financial Disclosure}

This work was supported by grants from Doctors Man Co., Ltd. The funders had no role in the study design, data collection and analysis, the decision to publish, or preparation of the manuscript.

\section{Conflict of Interest}

MS and EK receive advisory fees and research fees from Doctors Man Co., Ltd. MS receives advisory fees and research fees from Taiyo Nippon Sanso. The authors would like to declare 
the following patents/patent applications associated with this research: Author MS is the registered inventor of the following patents jointly filed by Keio University and Taiyo Nippon Sanso: hydrogen mixed gas supply device for medical purposes (patent number: 5631524), medicinal composition for improving prognosis after restart of patient's own heartbeat, and medicinal composition for improving and/or stabilizing circulatory dynamics after onset of hemorrhagic shock. In addition to these, there are three other patents in which the name of the inventions are only in Japanese and not described in English. Here are the names of the inventions, which are literal translation of Japanese into English: pharmaceutical compositions for reducing weight loss after organ harvesting (Joint application with Keio University and Taiyo Nippon Sanso), method for generating organ preservation solution containing hydrogen and organ preservation solution containing hydrogen (Joint application with Keio University and Doctors Man; Application number PCT/JP2019/045790). This does not alter our adherence to Journal of Clinical Medicine Research policies on sharing data and materials.

\section{Informed Consent}

Not applicable.

\section{Author Contributions}

MS designed the study, oversaw data collection, reviewed the literature, analyzed and interpreted the data, and drafted the manuscript. EK contributed to the design of the study, engaged in data collection and provided critical reviews of the manuscript. KS, YK, and GI contributed to data collection and provided critical reviews of the manuscript.

\section{Data Availability}

The authors declare that data supporting the findings of this study are available within the article.

\section{References}

1. Mizuno K, Sasaki AT, Ebisu K, Tajima K, Kajimoto O, Nojima J, Kuratsune $\mathrm{H}$, et al. Hydrogen-rich water for improvements of mood, anxiety, and autonomic nerve function in daily life. Med Gas Res. 2017;7(4):247-255.

2. Yoon YS, Sajo ME, Ignacio RM, Kim SK, Kim CS, Lee KJ. Positive Effects of hydrogen water on 2,4-dinitrochlorobenzene-induced atopic dermatitis in $\mathrm{NC} / \mathrm{Nga}$ mice. Biol Pharm Bull. 2014;37(9):1480-1485.

3. Fang S, Li X, Wei X, Zhang Y, Ma Z, Wei Y, Wang W. Beneficial effects of hydrogen gas inhalation on a murine model of allergic rhinitis. Exp Ther Med. 2018;16(6):5178-5184.

4. Ishibashi T, Sato B, Rikitake M, Seo T, Kurokawa R,
Hara Y, Naritomi Y, et al. Consumption of water containing a high concentration of molecular hydrogen reduces oxidative stress and disease activity in patients with rheumatoid arthritis: an open-label pilot study. Med Gas Res. 2012;2(1):27.

5. Zhang N, Deng C, Zhang X, Zhang J, Bai C. Inhalation of hydrogen gas attenuates airway inflammation and oxidative stress in allergic asthmatic mice. Asthma Res Pract. 2018;4:3.

6. Lu W, Li D, Hu J, Mei H, Shu J, Long Z, Yuan L, et al. Hydrogen gas inhalation protects against cigarette smoke-induced COPD development in mice. J Thorac Dis. 2018;10(6):3232-3243.

7. Guan WJ, Wei CH, Chen AL, Sun XC, Guo GY, Zou X, Shi JD, et al. Hydrogen/oxygen mixed gas inhalation improves disease severity and dyspnea in patients with Coronavirus disease 2019 in a recent multicenter, openlabel clinical trial. J Thorac Dis. 2020;12(6):3448-3452.

8. Zhang Y, Su WJ, Chen Y, Wu TY, Gong H, Shen XL, Wang YX, et al. Effects of hydrogen-rich water on depressive-like behavior in mice. Sci Rep. 2016;6:23742.

9. Li J, Wang C, Zhang JH, Cai JM, Cao YP, Sun XJ. Hydrogen-rich saline improves memory function in a rat model of amyloid-beta-induced Alzheimer's disease by reduction of oxidative stress. Brain Res. 2010;1328:152-161.

10. Ohsawa I, Ishikawa M, Takahashi K, Watanabe M, Nishimaki K, Yamagata K, Katsura K, et al. Hydrogen acts as a therapeutic antioxidant by selectively reducing cytotoxic oxygen radicals. Nat Med. 2007;13(6):688-694.

11. Hayashida K, Sano M, Kamimura N, Yokota T, Suzuki M, Maekawa Y, Kawamura A, et al. H(2) gas improves functional outcome after cardiac arrest to an extent comparable to therapeutic hypothermia in a rat model. J Am Heart Assoc. 2012;1(5):e003459.

12. Hayashida K, Sano M, Kamimura N, Yokota T, Suzuki M, Ohta S, Fukuda K, et al. Hydrogen inhalation during normoxic resuscitation improves neurological outcome in a rat model of cardiac arrest independently of targeted temperature management. Circulation. 2014;130(24):21732180.

13. Kumagai K, Toyooka T, Takeuchi S, Otani N, Wada K, Tomiyama A, Mori K. Hydrogen gas inhalation improves delayed brain injury by alleviating early brain injury after experimental subarachnoid hemorrhage. Sci Rep. 2020;10(1):12319.

14. Satoh Y, Araki Y, Kashitani M, Nishii K, Kobayashi Y, Fujita M, Suzuki S, et al. Molecular hydrogen prevents social deficits and depression-like behaviors induced by low-intensity blast in mice. J Neuropathol Exp Neurol. 2018;77(9):827-836

15. Hayashida K, Sano M, Ohsawa I, Shinmura K, Tamaki K, Kimura K, Endo J, et al. Inhalation of hydrogen gas reduces infarct size in the rat model of myocardial ischemia-reperfusion injury. Biochem Biophys Res Commun. 2008;373(1):30-35.

16. Yoshida A, Asanuma H, Sasaki H, Sanada S, Yamazaki S, Asano Y, Shinozaki Y, et al. H(2) mediates cardioprotection via involvements of K(ATP) channels and permeability transition pores of mitochondria in dogs. Cardiovasc 
Drugs Ther. 2012;26(3):217-226.

17. Katsumata Y, Sano F, Abe T, Tamura T, Fujisawa T, Shiraishi Y, Kohsaka S, et al. The Effects of hydrogen gas inhalation on adverse left ventricular remodeling after percutaneous coronary intervention for ST-elevated myocardial infarction- first pilot study in humans. Circ J. 2017;81(7):940-947.

18. Chen J, Zhang H, Hu J, Gu Y, Shen Z, Xu L, Jia X, et al. Hydrogen-rich saline alleviates kidney fibrosis following AKI and retains klotho expression. Front Pharmacol. 2017;8:499.

19. Qiu P, Liu Y, Zhang J. Recent advances in studies of molecular hydrogen against sepsis. Int J Biol Sci. 2019;15(6):1261-1275.

20. Matsuoka T, Suzuki M, Sano M, Hayashida K, Tamura T, Homma K, Fukuda K, et al. Hydrogen gas inhalation inhibits progression to the "irreversible" stage of shock after severe hemorrhage in rats. J Trauma Acute Care Surg. 2017;83(3):469-475.

21. Tamura T, Sano M, Matsuoka T, Yoshizawa J, Yamamoto R, Katsumata Y, Endo J, et al. Hydrogen gas inhalation attenuates endothelial glycocalyx damage and stabilizes hemodynamics in a rat hemorrhagic shock model. Shock. 2020;54(3):377-385.

22. Li S, Liao R, Sheng X, Luo X, Zhang X, Wen X, Zhou
$\mathrm{J}$, et al. Hydrogen gas in cancer treatment. Front Oncol. 2019;9:696.

23. Iuchi K, Imoto A, Kamimura N, Nishimaki K, Ichimiya $\mathrm{H}$, Yokota T, Ohta S. Molecular hydrogen regulates gene expression by modifying the free radical chain reactiondependent generation of oxidized phospholipid mediators. Sci Rep. 2016;6:18971.

24. Tamura T, Suzuki M, Hayashida K, Kobayashi Y, Yoshizawa J, Shibusawa T, Sano M, et al. Hydrogen gas inhalation alleviates oxidative stress in patients with post-cardiac arrest syndrome. J Clin Biochem Nutr. 2020; Epub ahead of print.

25. Kobayashi E, Sano M. Organ preservation solution containing dissolved hydrogen gas from a hydrogenabsorbing alloy canister improves function of transplanted ischemic kidneys in miniature pigs. PLoS One. 2019;14(10):e0222863.

26. Sano M, Ichihara G, Katsumata Y, Hiraide T, Hirai A, Momoi M, Tamura T, et al. Pharmacokinetics of a single inhalation of hydrogen gas in pigs. PLoS One. 2020;15(6): 0234626.

27. Kilkenny C, Browne WJ, Cuthill IC, Emerson M, Altman DG. Improving bioscience research reporting: the ARRIVE guidelines for reporting animal research. PLoS Biol. 2010;8(6):e1000412. 